\title{
Study on the basic mechanical characteristics of CRTS III slab ballastless track
}

\author{
Kunteng Zhu \\ School of Civil Engineering \\ Central South University \\ Changsha, China \\ 306353043@qq.com \\ Zhiping Zeng \\ School of Civil Engineering \\ Central South University \\ Changsha, China \\ 996510155@qq.com \\ Bin Wu \\ School of Civil Engineering \\ Central South University \\ Changsha, China \\ 956310155@qq.com
}

\author{
Bin Liu \\ School of Civil Engineering \\ Central South University \\ Changsha, China \\ 269036993@qq.com \\ Xianfeng $\mathrm{He}$ \\ School of Civil Engineering \\ Central South University \\ Changsha, China \\ 1239435840@qq.com \\ Dapeng Zeng \\ School of Civil Engineering \\ Central South University \\ Changsha, China \\ 458973255@qq.com
}

\begin{abstract}
In order to study on the basic mechanical characteristics of CRTS III type slab ballastless track structure, a product of independent research and development of China, we have established the spatial mechanical model of elastic and non-elastic cushion of CRTS III type slab ballastless track based on the large universal finite element software ANSYS. And we have calculated respectively the spatial mechanical characteristics of CRTS III type slab ballastless track under vertical train load, temperature gradient load and the coupling load of these two. The result shows that under temperature gradient load, track structure stress significantly increased when the model have inelastic cushion, the tensile stress of self-compacting concrete increases from 2.07MPa to 7.0MPa.This shows that: elastic cushion can significantly reduce the effect of temperature load on the track structure. Under these 3 conditions, the stress of track structures are less than its allowed stress.
\end{abstract}

Keywords-CRTSIII type slab ballastless track structures; temperature gradient; coupling load; Mechanical properties; the elastic cushion;

\section{INTRODUCTION}

Due to its high stability, high durability and high reliability, plate type ballastless track structure is currently widely used in domestic and international projects ${ }^{[1-3]}$. CRTSIII type slab ballastless track structures is a new type slab ballastless track and consisted of rails, fasteners, track slab, self-compacting concrete layer, insulating layer and reinforced concrete base and other components, which were self-designed in China. Track slab is prestressed concrete panels, under track slab perfusion self-compacting concrete, the retaining groove is set on the surface of the base to achieve mechanical limit boss, geotextile separation layer is set between selfcompacting concrete and base to release temperature stress ${ }^{[4]}$. In order to make further study on the mechanical property of CRTSIII type slab ballastless track structures, except experimental, we need establish the finite element model in finite element program to calculate the displacement and stress of the track structure components.

\section{ESTABLISH AND VALIDATE THE MODEL}

As shown in Fig .1, in CRTSIII type slab ballastless track structures finite element model, it applied BEAM 188 to simulate rail, SOLID65 to simulate track slab, selfcompacting concrete and base. In order to eliminate the stress concentration, 25 springs was used to simulate fastener. There is contact element between self-compacting concrete layer and base, and contact element between selfcompacting concrete layer boss and seat recess.
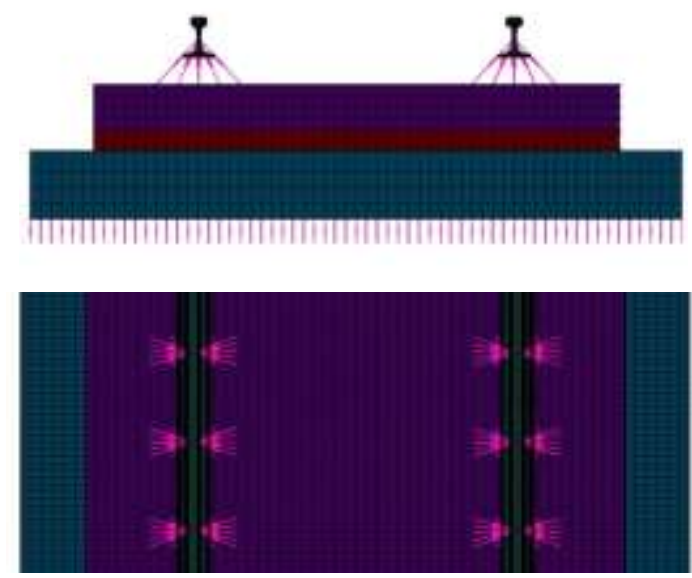

Figure 1. finite element model 
References[5]-Multi-scale finite element model for CRTS III type slab ballastless track structures, establish finite element model to calculate the CRTS III slab ballastless track in the same kind of conditions, the
References[6]-Study on the basic Mechanical Characteristics of CRTS III slab ballastless track, also final calculation results as shown in Table 1, showing good agreement with them.

TABLE I. COMPARING WITH THE LITERATURE MODEL RESULTS

\begin{tabular}{|c|c|c|c|}
\hline Calculation Method & This article & References [5] & References [6] \\
\hline $\begin{array}{l}\text { The maximum vertical displacement } \\
\qquad(\mathrm{mm})\end{array}$ & -0.443 & -0.472 & -0.495 \\
\hline $\begin{array}{l}\text { Self-compacting concrete maximum stress } \\
\qquad(\mathrm{MPa})\end{array}$ & 7.90 & 7.04 & 6.85 \\
\hline
\end{tabular}

\section{MECHANICAL PROPERTIES UNDER TRAIN LOAD}

EMU maximum axle load is $17 \mathrm{t}$, therefore, vertical design static wheel load is $85 \mathrm{kN}$. The power modulus is 3 ,which is based on non-ballasted track new research results at the speed of $350 \mathrm{~km} / \mathrm{h}$, as it is that the design of static wheel load is $255 \mathrm{kN}$. It took track structure intermediate position as the train load point, and in order to eliminate boundary effects, we selected the intermediate track slab for the study. The results were shown in Fig .2.

According to the stress and displacement cloud picture of track structure, the maximum tensile, compressive
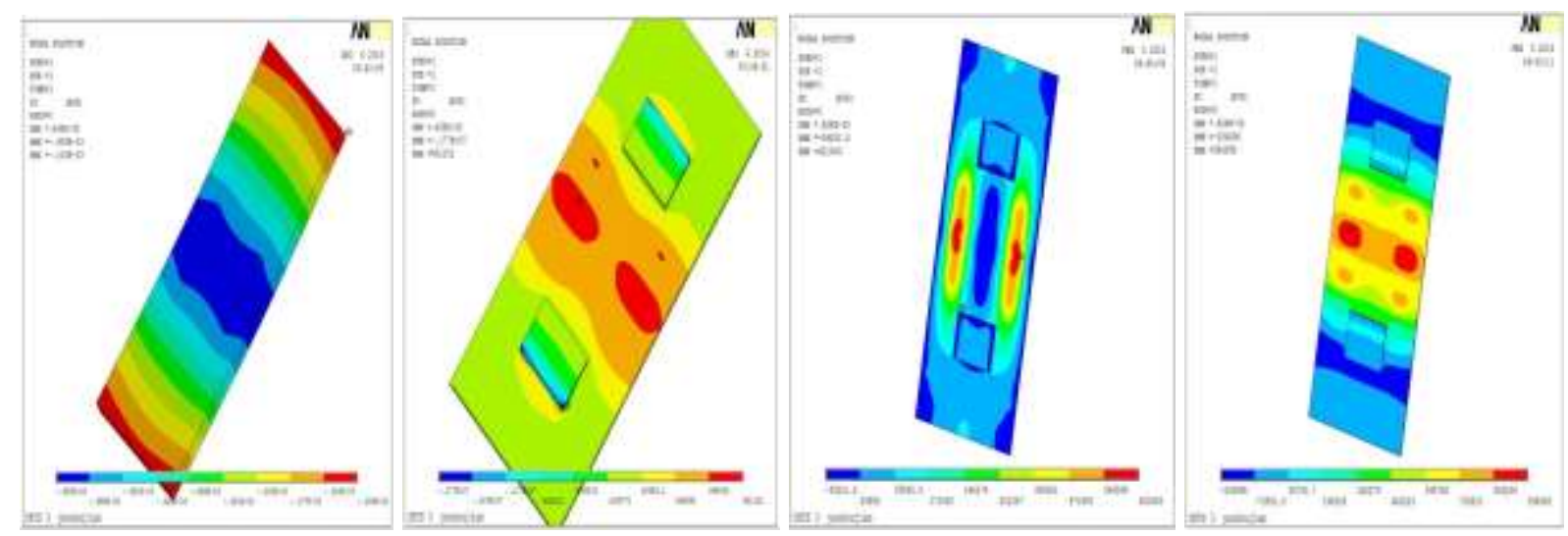

Figure 2. The stress and displacement cloud picture of track structure

TABLE II. THE MAXIMUM OF STRESS AND DISPLACEMENT

\begin{tabular}{|c|c|c|c|c|}
\hline \multirow{2}{*}{ Track structure } & \multicolumn{2}{|c|}{ Calculate index } & Elastic cushion & Inelastic cushion \\
\hline \multirow{4}{*}{ Track Slab } & compressive stress & $\mathrm{MPa}$ & -4.15 & -3.48 \\
\cline { 2 - 5 } & tensile stress & $\mathrm{MPa}$ & 0.97 & 0.72 \\
\cline { 2 - 5 } & displacement & $\mathrm{mm}$ & -0.43 & -0.43 \\
\hline \multirow{3}{*}{$\begin{array}{c}\text { Self-compacting } \\
\text { concrete }\end{array}$} & compressive stress & $\mathrm{MPa}$ & -0.87 & -0.84 \\
\cline { 2 - 5 } & tensile stress & $\mathrm{MPa}$ & 0.99 & 0.95 \\
\cline { 2 - 5 } & displacement & $\mathrm{mm}$ & -0.42 & -0.43 \\
\hline
\end{tabular}

\section{MECHANICAL PROPERTIES UNDER TEMPERATURE GRADIENT LOAD}

Assuming that track slab temperature gradient varies linearly, refering to German railway design specifications and related information of road surface of China, we can stress and displacement of track slab and self-compacting concrete were listed as shown in Table 2.

As is shown in the table 2, it can be seen that the tensile and compressive stress of track structure is less than its allowed tensile and compressive strength. Under train loads, the elastic cushion has a small impact on the vertical, transverse stress and displacement of track structure. 
temperature difference between the track slab surface and the bottom of the self compacting concrete is chosen as 26、20、14.5、-13、-10、- $7^{\circ} \mathrm{C} / \mathrm{m}$. A model with elastic cushioning is chosen. The results were shown in Fig .3.

According to the stress and displacement cloud picture of track structure, the maximum tensile, compressive stress and displacement of track slab and self-compacting concrete were listed as shown in Table 3.

As is shown in the table 3 , be the temperature gradient positive or negative, the maximum relative displacement of the track slab is a linear function of the temperature gradient. With the elastic cushion ,under the temperature gradient load, the tensile and compressive stress of track structure is less than its allowed stress.

As is shown in the table 3, we can see that under the temperature gradient load, track structure stress significantly increased when the model have inelastic cushion. The tensile stress of self-compacting concrete increases from $2.07 \mathrm{MPa}$ to $7.0 \mathrm{MPa}$, this shows that: elastic cushion can significantly reduce the effect of temperature load on the track structure.
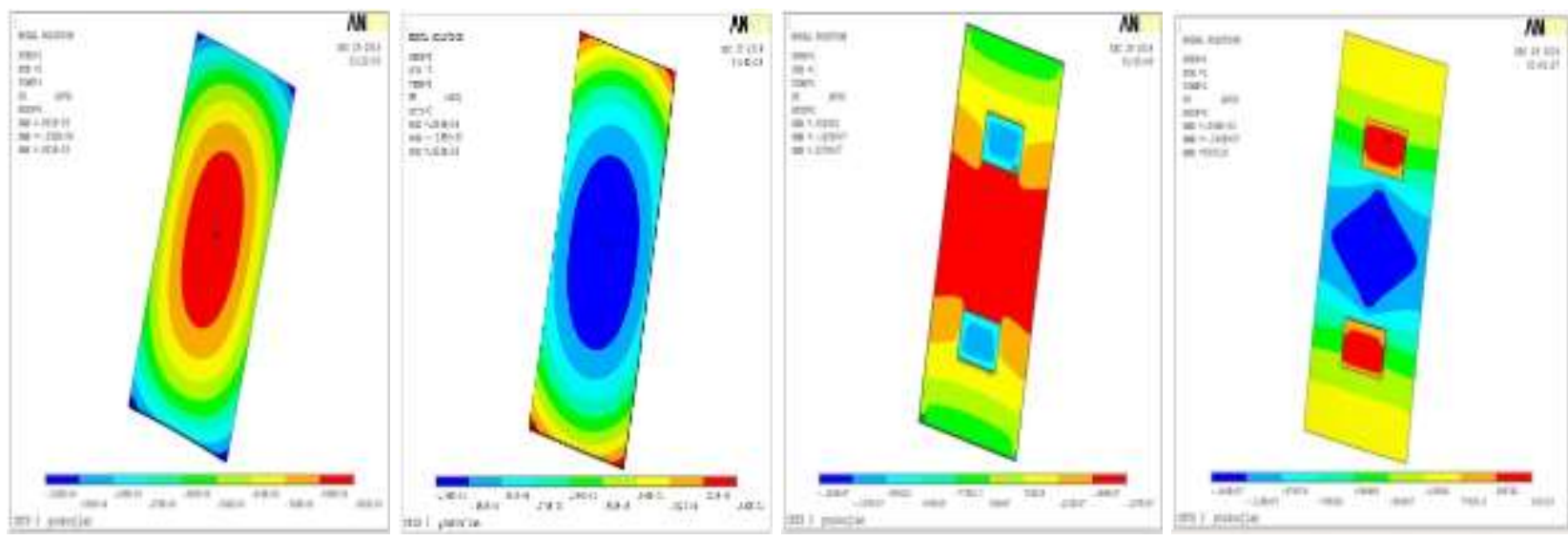

Figure 3. The stress and displacement cloud picture of track structure

TABLE IV. THE MAXIMUM OF STRESS AND DISPLACEMENT

\begin{tabular}{|c|c|c|c|c|}
\hline \multicolumn{3}{|c|}{ Temperature difference between track slab and base $\left({ }^{\circ} \mathrm{C}\right)$} & 26 & -13 \\
\hline \multirow{3}{*}{ Track Slab } & compressive stress & $\mathrm{MPa}$ & 1.48 & 2.08 \\
\hline & tensile stress & $\mathrm{MPa}$ & -4.01 & -0.60 \\
\hline & displacement & $\mathrm{mm}$ & 2.24 & -1.27 \\
\hline \multirow{3}{*}{ Self-compacting concrete } & compressive stress & $\mathrm{MPa}$ & 7.00 & 0.68 \\
\hline & tensile stress & $\mathrm{MPa}$ & -4.83 & -1.71 \\
\hline & displacement & $\mathrm{mm}$ & 2.24 & -1.27 \\
\hline
\end{tabular}

\section{MECHANICAL PROPERTIES UNDER COUPLING LOAD}

This section mainly analyzes mechanical characteristics of track structure under the common effect of the temperature load and the train load. As for the temperature gradient load, we only consider the maximum one, and take the intermediate position of track structure as the point for train load. The results were shown in Fig .5.

According to the stress and displacement cloud picture of track structure, the maximum tensile, compressive stress and displacement of track slab and self-compacting concrete were listed in Table 5.

As is shown in table 5, under the effect of coupling load, the track slab displacement is smaller than the one only affected by the temperature gradient This shows that static train load can reduce the upward displacement of track slab which is affected by the temperature gradient load. 

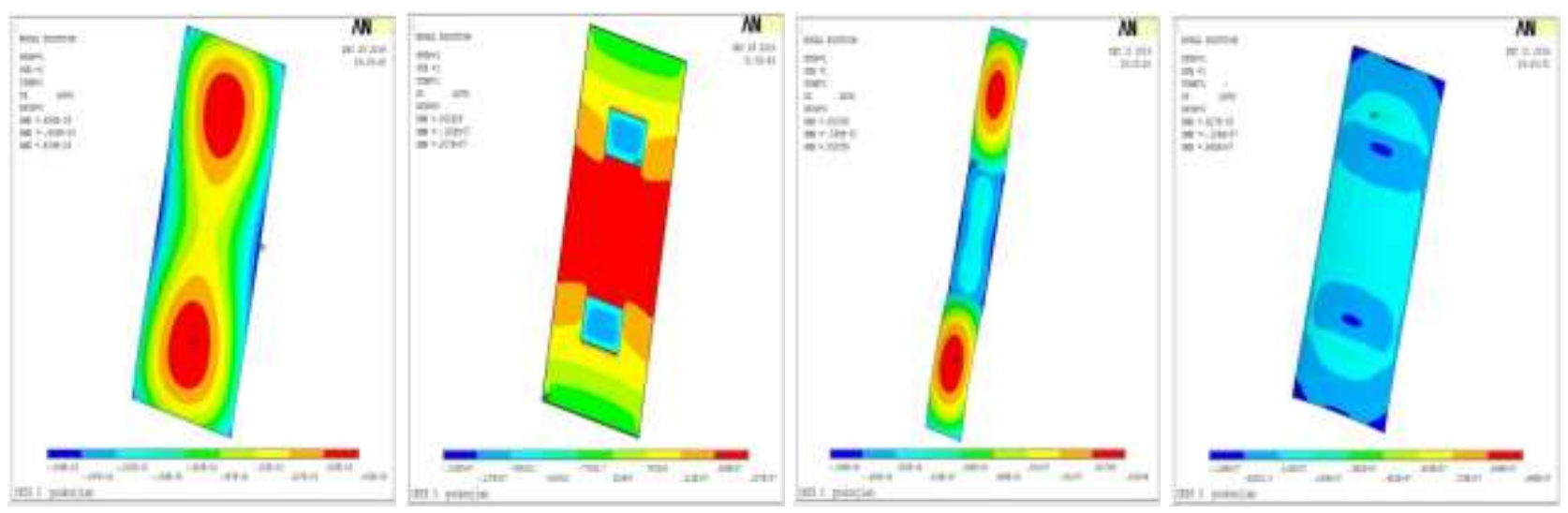

Figure 5. The stress and displacement cloud picture of track structure

TABLE V. THE MAXIMUM OF STRESS AND DISPLACEMENT

\begin{tabular}{|c|c|c|c|}
\hline \multirow{2}{*}{ Track structure } & \multicolumn{2}{c|}{ Calculate index } & Maximum \\
\hline \multirow{3}{*}{ Track Slab } & compressive stress & $\mathrm{MPa}$ & -0.84 \\
\cline { 2 - 4 } & tensile stress & $\mathrm{MPa}$ & 2.71 \\
\cline { 2 - 4 } & displacement & $\mathrm{mm}$ & -0.45 \\
\hline \multirow{3}{*}{ Self-compacting concrete } & compressive stress & $\mathrm{MPa}$ & -8.2 \\
\cline { 2 - 4 } & tensile stress & $\mathrm{MPa}$ & 7.27 \\
\cline { 2 - 4 } & displacement & $\mathrm{mm}$ & -0.45 \\
\hline
\end{tabular}

\section{CONCLUSION}

(1) Under train loads, the elastic cushion layer had a small effect on stress and displacement on each vertical and transverse layer of track structure. The tensile and compressive stress of track structure are smaller than its allowed stress.

(2) Be the temperature gradient positive or negative, the maximum relative displacement of the track slab is a linear function of the temperature gradient. Under temperature gradient load, elastic cushion can significantly reduce the effect of temperature load on the track structure.

(3) Compared to the previous two working conditions, under coupling load, the maximum stress increase. Compared to positive temperature gradient load, under coupling load, track slab relative displacement decrease.

\section{ACKNOWLEDGMENT}

The research described in this paper was financially supported by the Science and Technology Foundation of China Railway Corporation (Grant No. 2013G003-A-3); the Joint Funds of the National Natural Science Foundation of China (Grant Nos. U1334203 and U1134209); the National Key Technology R\&D Program (Grant No. 2013BAG20BH00); the Teacher Research Fund of Central South University of China (Grant No. 2013JSJJ021); the Open Fund Project of Hunan
Provincial University Innovation Platform of China (Grant No. 12K007)

\section{REFERENCES}

[1] Journal of Railway Science and Engineering : Experimental study on mechanical characteristics of CRTS II slab track under the vertical load of train.

[2] China Railway Press:Ballastless track structures of high speed railway.

[3] Anhua Wang. Study on the durability of CRTS III Ballastless Slab Track. Beijing Jiaotong University,2012: 1-10.

[4] Journal of Railway Science and Engineering: Dynamic response of different ballastless track sub grade.

[5] China Railway Press: Multi-scale finite element model for CRTS III type slab ballastless track structures.

[6] Chengxiao Wang. Study on the basic Mechanical Characteristics of CRTS III slab ballastless track.[D]. Central South University, 2011: $1-10$.

[7] MRT Productions: Modern railway track.

[8] Southwest Jiaotong University Press:Finite element analysis on stresses in slab track structures on soil subgrade $[\mathrm{J}]$.

[9] Beijing University of Technology Press: Influence of loading rate on com-pressive strength of CA mortar[J].

[10] Journal of railway science and engineering:Study on the mechanical characteristics of the self-compacting concrete of CRTS III slab ballastless track.

[11] Southwest Jiaotong University Press:Finite element analysis on stresses in slab track structures on soil subgrade $[\mathrm{J}]$. 